\title{
Some Temporarily Successful Experiences along Three Decades of Failure: Crime and Public Policy in Brazil
}

\author{
Edited by Renan Springer de Freitas* and Ludmila Ribeiro*
}

Federal University of Minas Gerais, Brazil

\section{INTRODUCTION}

The title of this Special Issue is meant to highlight the fact that in the last decades Brazil has failed to reduce violence and to assure basic civil rights for its population in spite of the adoption of public security policies that happened to be successful elsewhere. As one of the contributors of this Issue put it: "the homicide reduction programs carried out in Brazil over the last two decades have been formulated, in their intrinsic characteristics, in line with what the literature of the area identifies as good practices and actions with potential for successful violence reduction." ${ }^{1}$ However, we can learn from the same Author that since the 1980s the national homicide rate has grown by an average of $20 \%$ a year so that in 2016 we reached 61,000 intentional violent deaths per year - or 29.7 deaths per 100,000 inhabitants. Nowadays, although Brazilian population amounts to only $3 \%$ of world population, Brazil alone accounts for an average of $12 \%$ of the world's homicides. This rate includes the police victimization numbers: 11 people are killed every day by the police forces and the risk of a police officer being killed is three times higher than the general population. $^{2}$

Nevertheless, we also managed to have some temporary successes. In recent decades we could witness some local experiences of public security policy which proved to be very successful at first, but after some time it was no longer effective. This pattern could be seen in the most different social, economic and political contexts, such as the ones which are peculiar to such different states as São Paulo, Rio de Janeiro, Distrito Federal (where is located Brasilia, the Federal Capital), Pernambuco and Minas Gerais. What

*Address correspondence to this author at the Federal University of Minas Gerais, Brazil; E-mail: springer@fafich.ufmg.br, ludmila.ribeiro@gmail.com, ludmila.ribeiro@crisp.ufmg.br

${ }^{1}$ See especially Lima's contribution to this volume.

${ }^{2}$ See, once again, Lima's contribution to this volume. accounts for this astonished similarity of results regardless the political and ideological differences among the different local governments which implemented the public safety policies?

The present Issue gathers seven contributions by distinguished scholars on criminality in Brazil, some of which took part directly in the formulation and implementation of public safety policies in different states of Brazil. It has two parts. The first one, composed by the first three contributions, addresses the general problem of Brazilian persistent failure to reduce violence even with the help of policies which are worldwide recommended. This problem is directly addressed by Renato Sérgio de Lima in his paper "Violence and public safety as a democratic simulacrum in Brazil", and by Claudio Beato and Andréa Silveira, in their paper "Preventing crimes: A comparative perspective, Brazil, Latin America and U.S.A". The third paper of the first part, "Public Security and Policy Networks in Brazil", by Arthur Trindade M. Costa, also addresses this issue, although this is not his main concern. His contribution can also be read as illuminating the specific case of violence in Brasilia's schools.

The second part is focused on particular experiences of success followed by failure, such as the ones peculiar to the Brazilian states of Rio de Janeiro, Pernambuco, Minas Gerais, and Brazilian Amazon Region. The contribution by Michel Misse addresses the experience of Rio de Janeiro, the one by José Luiz Ratton and Jean Daudelin addresses the experience of Pernambuco, the one by Ludmila Ribeiro and Ariane Gontijo Lopes addresses the experience of Minas Gerais, and the contribution by Jean-François Yves Deluchey and Amanda Laysi Pimentel Dos Santos addresses the experience of Brazilian Amazon.

\section{$* * *$}

The first three contributions lead us directly to the distinctive feature of the security safety policies which can be said to be the very root of our persistent failure. 
We will borrow the words by Beato and Silveira to describe it: policies in the crime and justice area have been accomplished in blind flight, without instruments and with purely impressionist orientation. The first three papers of this Issue can be read as an effort towards understanding the nature, the persistence, and the implications of this "blind flight", as well as towards showing some way out of it.

Let us start by Beato and Silveira themselves. Their paper draws our attention to the fact that several programs that have already been implemented in Brazil had no knowledge at all about the results of previous implementations. To act with this lack of knowledge is to take a blind flight. Let us quote them again: there is no evaluation of the costs of these programs in the presence of the reached results, nor their effectiveness. What about their effective impact on violence and crime rates? What aspects have fitted better? What is the necessary time gap to produce some effects? What types of combinations are necessary for the production of promising results? How to prevent unnecessary expenses with approaches known to be useless, even so well intentioned? Their comparative study shows that elsewhere this problem has already been solved a long time ago, especially in USA, where the police makers are concerned with questions of this nature since the 1970s.

Lima's paper, on its turn, draws our attention to a "blind flight" that is implied in the proliferation of programs which are not articulated by any system of guidelines - especially a system which assure the preservation of the basic civil rights of the population. As the reader will see, Lima selected eight homicide reduction programs to study, which were implemented in eight different states of the Federation. His main point is that although such programs followed, in broad lines, successful recommendations and practices adopted around the world, having thereby a potential impact in the short and medium term, they can only be truly successful by ceasing to be mere programs and becoming permanent actions that could effectively change the policing standards as well as the country's criminal and penitentiary policies.

The questions then arise: how to make this transition possible? What has prevented it from occurring? Lima's answer to the latter question is twofold. On the one hand, he argues that the widely shared view among Brazilian population that criminals are not allowed to basic civil rights (57\% of Brazilian population would agree to kill them all!) has an unequivocal impact on the "design and implementation of violence reduction programs in Brazil, for [this view] spells out a strong symbolic battle for the legitimacy of killing and, therefore, shapes political and institutional priorities and positions. As a matter of fact, some deaths are even accepted as inherent in the 'war' instituted between segments of the Brazilian society, which often reinforce not only violence itself, but the perverse division between 'the good citizens' and 'the criminals', while regulated guarantee of the social and political rights for the first group (...) and sparing the rigor of law and revenge for the latter." From this perspective, "if we want to understand the limits and potentialities of violence reduction programs in Brazil, we must note that the socio-cultural categories 'good citizen' and 'criminal' seem to respectively replace, through a racial and economic profile, the socioeconomic categories of the 'hard worker' and the 'bum', which structured the social relations and the relations between the police force and the society in the country until the 1970s (...). Furthermore, dealing with these new categories will often be more analytically important than merely adopting new technologies and management tools for the operation of existing policing standards. This is because, in fact, these categories will, in moral terms, determine what police actions will be regarded as 'right' or 'wrong', indicating that the democratic recovery [since 1985, after 21 years of an authoritarian regime] has not been able to change the paradigm of citizenship in Brazil, whose hallmark has always been grounded on a system of differentiated citizenship, which treats some individuals as citizens who deserve rights while others do not." According to Lima, this is the reason why the murder of "good citizens" by "criminals" goes hand in hand with the murder of criminals by police officers and of the latter by the former. From 2015 to 2016, for example, the number of police use of deadly force increased by $26.8 \%$ and police officers killed, $23.1 \%$. From this perspective, one cannot treat the death of "good citizens", "criminals" and police officers as having no bearing on each other. To do so is another way to take a "blind flight".

But, we would say, there is a kind of "hidden force" impelling to such an adventurous flight: as Lima explains, our legislation and the jurisprudence of our courts do not define what constitutes security and public order, they simply determine which institutions are responsible for them. In the absence (or in the multiple presences) of legal boundaries, it is up to the legal doctrine and the daily practice of law enforcement 
and other institutions of the criminal justice system to define who will be the object of their attention and vigilance. Also, insofar as the democratic governance instruments of the police mandates have yet to be structured (mechanisms of control, transparency and accountability), the tendency is that - given the path dependency of the criminal justice and public security organizations - the political leaders demand punctual and discontinuous actions, leaving to the police the task of accomplishing the expected goals. There is an excess of autonomy that is detrimental to society and to the law enforcement institution itself.

In line with this argument by Lima, Costa reminds us that although no one disputes that the rate of criminality in Brazil reached an alarming growth, there is no consensus whatsoever on what problems should be the prioritized and what are the most appropriate solutions to solve them. On the contrary, there is an intense dispute between the various actors that compose the field to determine the main problems and their solutions. The groups compete to form the agenda because no political system can process and solve all the problems at the same time. Although security is a common good, there are several competing interests: which neighborhoods will receive more police officers and the best equipment, which security career will be prioritized, and which social groups have received the main attention and care are some examples. And, of course, who will fund the policy.

It would be naive, however, to expect a consensus in this regard because, as Costa explains, public security policies are not limited to police organizations. They often involve the participation of other organizations and actors. Different policy networks are then formed in relation to each specific issue. Being this the case, each network covers a variety of conflicts, since there may be distinct diagnoses of the problems to be faced, as well as their different solutions. The actors related themselves, converging or diverging about the interpretation of these problems, assign relevance, strategies and actions to deal with them.

Costa illustrates his view by studying violence in Brasilia's schools. He argues that as it happens to occur elsewhere, in Brasilia the crime-related problems in schools have traditionally been treated as a police matter that should be solved by the police. However, it is known that to deal with these kinds of problems, police action is not enough. It is necessary to form a public policy network with the participation of other institutions to present adequate and effective responses. In the case of Brasilia, a public safety policy in schools cannot dispense the professionals of the Psychosocial Care Center, the Social Assistance Reference Center, the Children Protection Councils, as well as the initiatives developed in civil society for conflict administration. So, in June 2015, the Public Security Secretariat (SSP) start to hold meetings aimed to establish a public policy network focused on crimerelated problem in Brasilia schools. The network should include representatives from different governmental areas, such as education, health, justice, labor, culture, sports, budget, besides the police. Despite being one of the main problems pointed out by teachers, students, staff and parents, the formation of the network did not prosper. This was partly due to the difficulties that the SSP had to prepare a working agenda with the several actors involved. It is clear that structuring a network requires more than willingness to collaborate. An agency needs to coordinate, plan, and articulate actions. It is necessary that this institution be endowed with great capacity for governance. This definitively was not the case of Public Security Secretariat of Federal District (Brasilia).

Of course these brief remarks do not make justice to the richness of the first three papers, but point to the fact that each of these papers sheds its own specific light on the "blind flight" that became the earmark of the safety public policy in Brazil the last three decades - a "blind flight" that prevents the persistence of the successful localized experiences that are the concern of the papers that compose the second part of this Issue.

In the second part of this issue, the four papers indicate the reasons for this blind flight in public safety policies. The lack of proper data, the absence of a rational model of governance and the manipulation of the goals to reduce homicide by the police forces are the three main ones that contribute to the temporary success of the security plans implemented in the Amazon area and the states of Rio de Janeiro, Pernambuco and Minas Gerais.

All the authors highlight the fact that Brazil does not have an integrated database for crime reports and criminal justice activities,let alone a culture of data reporting, as is so strongly present in the US, for example. In Brazil we do not rely on a unified criminal database, with open access, such as the Federal 
Bureau of Information online system, which brings facts and figures associated with different patterns of crime or phases of criminal proceedings. In Brazil, instead, we have scattered pieces of information which need to be collected from various and unsystematic sources, a fact that hampers institutional performance comparisons within the criminal justice system, including aspects related to cases cleared by the police, and punishment dispensed in the judicial phase. In addition, due to the lack of official data, researchers cannot analyze criminal behavior over time or evaluate the efficiency of the criminal justice system. Thus, it is impossible to have a well-flown flight in the public safety area since we do not have any reliable information to count on for planning a program.

The lack of data that affects crime monitoring in Brazil also has implications for the construction of a model of governance that puts together the prevention and repression policies and the agencies responsible for their implementation. In this scenario, each criminal justice organization implements its own activities, plans without any sort of accountability. The officers make their decision based solely on their instincts, only to satisfy the interests of their own. The single thing that appears to matter to the public security agencies in Brazil is retaining high profits at the end of the month.

This brings us to the third point that the authors emphasize, which is suspicion of police activity, always seen as biased, corrupt and illegal. The police forces are the major problem of safety policies developed in Brazil. They are managing the lucrative political merchandise described by Misse. They are producing the violence that public policies aim to reduce through their engagement in Militias or Death Squads, as stressed by Deluchey and Santos. In addition, they are falsifying the criminal reports in order to receive the bonus to be paid for the homicide reduction, as argued by Ribeiro and Lopes. As stressed by Ratton and Daudelin, they are taking advantage of the political moments to deconstruct the new models of governance and accountability. After reading these four papers, there is no doubt that the cabin assistants of this blind flight are the police forces.

The paper by Deluchey and Santos focuses on how the absence of a proper public safety policy has implied in unprecedented growth of the homicide rates: $87 \%$ in ten years in the Amazon area. The main problem of the region appears to be the "conquest frontiers" to use the title of a classic book regarding how the expansion of urban areas in the Amazon area would lead to conflicts and violence. ${ }^{3}$ Another variable that accounts for the spread of homicides in the area is that of police killings. In this specific issue, the support of a significant part of the Amazon population endorses the militias and death squads as desirable organizations, as an agency that separates the killable ones (in Agamben terms) from the ones that deserve to still be living. This sort of justice without trial explains why young, black and poor males are the most likely to be murdered - in the area and in Brazil. These are the non-citizens, the ones that are included solely through their exclusion of citizenship rights.

Misse guides us depicting the major problems of the criminal justice system that imply in what he calls "social accumulation of violence". He argues that this insurgency in violence happens as it is almost impossible to penalize those who committed a felony in Brazil. Since these organizations are inefficient in reporting a crime and appointing a suspect, more than $90 \%$ of all homicides perpetrated in the country remain unpunished. Thus, in order to guarantee some degree of safety in the areas most affected by crime, some police officers offer their services as vigilantes, a provision that either allows for the functioning of drug markets or the security of citizens that live in the area. If this fact increases justice without trial, the unprecedented rise in the number of people held in custody in Brazil - specifically the pretrial prisoners has enlarged the organized crime networks. It means that prison sentences have been transformed, over the last twenty years, into a kind of training and a tool for strengthening the criminal networks.

Once a prisoner finishes his term, he is formally a member of a group that sells illicit goods and provides justice, a word that has multiple meanings in São Paulo and Rio de Janeiro. Misse accentuates that in both cities the police forces are unable to change how these criminal organizations work, especially, in terms of the level of violence that they use to protect their markets. It happens because the police are also responsible for the existence of these illegal markets. This is what he calls "political merchandise", a commodity that "can be produced by the privatization of state attributions by a government employee (this is the case of the variety of exchanges known as "corruption"), or can be produced simply by the possession of sufficient information, strength, power or violence to require an individual or

${ }^{3}$ SCHMINK, Marianne; WOOD, Charles H. Contested frontiers in Amazonia Columbia University Press, 2010. 
social group to enter into a relationship of exchange (this is the case of the so-called "extortion")."

According to Misse, what makes criminal activity in Brazil something peculiar is the fact that the reproduction of criminal organizations becomes particularly dependent on agreements and political exchanges with public agents, among which the police (an organization that controls the legal use of weapons and strategic information) constitute one of the main types. Because this political merchandise frames the illegal markets, they are intricate to everyday life in the slums. Therefore, it is almost impossible to establish a community policing program that can bring safety to favelas without police officers being bribed to accomplish it. The Police Pacification Units have shown how unbalanced this relationship between legal and illegal provision of safety is. Once the arrival of pacification starts to decrease the profits of the drug market, the corrupt police officers and criminal networks start to screen for the gaps that could be used to return to the previous situation, when political merchandise could be negotiated without major problems. The fact that this program was almost discontinued in the beginning of 2018 - after years of decreasing homicide rates and police killings - is a sample of how the public safety policies are trapped into a vicious cycle, leading to other blind flights such as the federal intervention of the Armed Forces in Rio de Janeiro, announced on February $16^{\text {th }} .4$

The vicious cycle of blind flights of public safety policies can be seen as the major subject of the last two papers of this Special Issue. Ratton \& Daudelin's as well as Ribeiro \& Lopes's paper argues that a specific model of governance of public safety policies is able to reduce homicide, especially when the police forces are engaged with these goals. However, despite all innovations presented and the excellent results obtained in terms of crime reduction, the states of Pernambuco and Minas Gerais ended up discontinuing the model implemented at the cost of a rise in violent crimes.

In Pernambuco, the State Plan for Public Security (called Pact for Life) was, in the vision of Ratton and Daudelin, the "distinguishing factor responsible for the fall in homicide rates". In Minas Gerais, the resultsbased agreement that supported the Emergency Public

${ }^{4}$ News related to this federal intervention are available on: https://www.nytimes.com/2018/02/16/world/americas/brazil-rio-militarysecurity.html, acessed on February 19th.
Safety Program was responsible for crime reduction in general terms. The roots of these two public policies are the same: a well-flown flight demands a map that shows the routes, the temperature inside and outside the aircraft as well as the points of turbulence. Both public policies were constructed through partnerships between the government and academic institutions, in order to draw the diagnosis of the problem of crime and public security and address areas to be prioritized in order to achieve sustainable crime reduction.

Also, Minas Gerais and Pernambuco safety policies combine social prevention of crime with the repression of felonies, buttoned up by incarceration. In order to guarantee proper monitoring of the targets and accomplishment of the goals, a management system was developed. In both institutional arrangements, a committee chaired by the State Governor (Pernambuco) or State Secretary of Social Defense (Minas Gerais) evaluates the actions implemented under the specific plans developed in order to allow for payment of the bonus for the police forces. Even the name of both secretaries responsible for the coordination of public safety in the two states was the same: Secretariat of Social Defense.

The two papers inform that the integration promoted by the State Secretariat of Social Defense did manage to institutionalize itself for some time, reducing crime, increasing safety and making the police forces accountable for their role in homicide rates. Nonetheless, political transformations led to the resumption of the institutional arrangement that existed prior. In Pernambuco, the homicide rates achieved the highest point in 2017 and, in Minas Gerais, the Secretary of Social Defense was divided into Secretariat of Public Security and State Secretariat of Prison Administration and violent crime has been increasing in recent years.

If Police Pacification Units, the Pact of Life and Result-based agreements were successful for a while, the question that remains unanswered is the following: why are these safety policies not able to last in decreasing violent crime? Why do these initiatives that can be seen as a well-flown flight not last for more than a few years?

Misse's paper is the one which addresses these issues more directly. According to him, the abovementioned initiatives are not institutionalized because when they came into force the political merchandise was neither available nor able to produce profits. Then, 
when the police forces are able to point out a gap to recognize even a small lack of state of control in certain areas, they use these opportunities as a means to increase their power over legal and illegal activities, raising their profits again.

To transform the temporarily successful experiences along three decades of failure into something able to reduce crime sustainably, the police forces must be reformed. A construction of new police forces is the departure point in order to produce proper crime data, based on reliable registers that can show where and when crime is taking place, who the perpetrators are and why they are committing a crime. Without data, it is impossible to drive the public intervention towards the main public safety problems.

Without reliable information and analytics producing the diagnosis for the problem of violence, the police forces will still be focusing on low level drug cases, that only bring minor offenders to prison, increasing the number of pretrial detainees and the size of the criminal networks. If repression in itself were the most suitable answer for crime problems, Brazil would be one of the safest countries in the world, since it has the third largest penitentiary population. There is no doubt, after reading the papers that analyze the cases of success that prevention, based on smart statistics and policing, is the better option.

An urgent police reform is also needed in order to reduce the rates of homicide, since police killings are responsible for a high percentage of all murder cases registered in Brazil. It is unthinkable to draw up a public safety policy without reducing this level of state violence, that deprives the poor, black and young male citizens of their most basic right: life.

In summary, a democratic police force is needed to guarantee reliable criminal records, to provide justice with trial and to reduce homicides. As argued by all the papers put together in this special issue, if the police are not the main problem towards a safer society in Brazil, it is a decisive component of this blind flight.

Received on 25-02-2018

Accepted on 27-02-2018

Published on 11-04-2018

DOI: https://doi.org/10.6000/1929-4409.2018.07.07

(C) 2018 Freitas and Ribeiro; Licensee Lifescience Global.

This is an open access article licensed under the terms of the Creative Commons Attribution Non-Commercial License (http://creativecommons.org/licenses/by-nc/3.0/) which permits unrestricted, non-commercial use, distribution and reproduction in any medium, provided the work is properly cited. 